\title{
DETERMINANTES DA REMUNERAÇÃO DOS EXECUTIVOS E SUA RELAÇÃO COM O DESEMPENHO FINANCEIRO DAS COMPANHIAS ${ }^{1}$
}

\author{
Paulo Vitor Souza de Souza ${ }^{2}$ \\ Ricardo Lopes Cardoso ${ }^{3}$ \\ Simone Silva da Cunha Vieira ${ }^{4}$
}

http://dx.doi.org/10.1590/1413-2311.175.63859

\begin{abstract}
RESUMO
Os incentivos financeiros são mecanismos utilizados para alinhar os objetivos do agente aos do principal. Este estudo objetiva verificar a relação dos determinantes da remuneração dos executivos, com o desempenho financeiro e de mercado das companhias brasileiras de capital aberto, listadas na BM\&FBovespa. Os dados foram obtidos através de análise dos formulários de referência, disponibilizados pela Comissão de Valores Mobiliários (CVM). O presente estudo classifica-se como exploratório com abordagem quantitativa. Foram encontradas 228 empresas após levantamento das companhias que disponibilizavam essas informações, sendo essa, a amostra que compõe a pesquisa. Foi utilizado o teste de regressão linear múltipla, com dados em painel, para testar a relação entre remuneração e desempenho das companhias entre os anos de 2011 a 2013. Foram encontrados fatores financeiros e fatores não financeiros como determinantes da remuneração nas companhias brasileiras de capital aberto. O teste de regressão identificou que há relação positiva e significativa do desempenho financeiro, com as remunerações baseadas em indicadores financeiros e não financeiros, em conjunto, e remunerações baseadas apenas em indicadores não financeiros. $\mathrm{O}$ desempenho de mercado não obteve significância estatística com a remuneração dos executivos. Estes resultados evidenciam que planos de incentivos que se baseiam em indicadores financeiros, não alinham os interesses dos agentes aos dos principais. A ausência de resultado entre desempenho de mercado com os sistemas de remuneração, afirma que os planos de remuneração não alinham os interesses do principal e agente.
\end{abstract}

Palavras-Chave: Remuneração dos Executivos. Problema da Agência. Política de Incentivo. Indicadores Financeiros e Não Financeiros.

\section{DETERMINANTS OF THE REMUNERATION OF EXECUTIVES AND ITS RELATIONSHIP WITH THE FINANCIAL PERFORMANCE OF COMPANIES}

\footnotetext{
ABSTRACT

${ }^{1}$ Recebido em 08/04/2016; aprovado em 20/03/2017.

${ }^{2}$ Universidade do Estado do Rio de Janeiro - paulosouzx@ gmail.com.

${ }^{3}$ Universidade do Estado do Rio de Janeiro - ricardo.lopes.cardoso@ fgv.br.

${ }^{4}$ Universidade do Estado do Rio de Janeiro - simoneantonio@uol.com.br.

REAd | Porto Alegre - Vol. 23 - No Especial - Dezembro 2017 - p. 4-28
} 
Financial incentives are mechanisms used to align the goals of the agent to the principal. This study aims to investigate the relationship of the determinants of executive compensation with the financial and market performance of Brazilian companies traded listed on BM \& FBovespa. Data were obtained through analysis of the reference forms provided by the Brazilian Securities Commission (CVM). The study is classified as exploratory with a quantitative approach. 228 companies were found after surveying the companies that provide what this information, which is the sample composing the research. We used the multiple linear regression with panel data to test the relationship between remuneration and performance of companies between the years 2011 to 2013. We found financial factors and non-financial factors as determinants of pay in Brazilian companies traded. Regression testing identified that there is a positive and significant relationship of financial performance, with remuneration based on financial and non-financial indicators together and pay only based on non-financial indicators. The market performance did not reach statistical significance with executive compensation. These results show that incentive plans that are based on financial indicators do not align the interests of agents to the main. The absence of a result between market performance pay systems states that compensation plans do not align the interests of principal and agent.

Keywords: Executive's Compensation. Agency's Problem. Incentive Policy. Financial and Non-Financial Indicators.

\section{DETERMINACIÓN DE LA COMPENSACIÓN DE EJECUTIVOS Y SU RELACIÓN CON EL RENDIMIENTO FINANCIERO DE EMPRESAS}

\section{RESUMEN}

Los incentivos financieros son mecanismos utilizados para alinear las metas del agente al principal. Este estudio tiene como objetivo investigar la relación de los factores determinantes de la remuneración de los ejecutivos con el desempeño financiero y el mercado de las empresas brasileñas negociados en la BM \& FBovespa. Los datos fueron obtenidos a través del análisis de las formas de referencia proporcionados por la Comisión de Valores de Brasil (CVM). El estudio se clasifica como exploratorio con enfoque cuantitativo. 228 empresas se encontraron luego de encuestar a las empresas que ofrecen lo que esta información, que es la muestra de la composición de la investigación. Se utilizó la regresión lineal múltiple con datos de panel para poner a prueba la relación entre la remuneración y el rendimiento de las empresas entre los años 2011 y 2013. Encontramos factores financieros y no financieros factores como determinantes de la remuneración en empresas brasileñas negociados. La prueba de regresión identificó que existe una relación positiva y significativa de rendimiento financiero, con una remuneración basada en indicadores financieros y no financieros en conjunto y pague basa en indicadores no financieros. El comportamiento del mercado no alcanzó significación estadística con la compensación de ejecutivos. Estos resultados muestran que los planes de incentivos que se basan en indicadores financieros no se alinean los intereses de los agentes a la principal. La ausencia de un resultado entre los sistemas de pago por desempeño de mercado establece que los planes de compensación no se alinean los intereses del principal y el agente.

Palabras-Clave: Remuneración de ejecutivos. Política de incentivos. Problemas de Agencia. Indicadores Financieros y no Financieros.

REAd | Porto Alegre - Vol. 23 - No Especial - Dezembro 2017 - p. 4-28 


\section{INTRODUÇÃO}

O sistema de incentivos oferecido aos gestores pode ser utilizado como ferramenta para o alinhamento dos interesses dos gestores aos dos proprietários. As formas de compensação aos gestores das grandes companhias têm sido muito discutidas em pesquisas empíricas na área de contabilidade financeira, pois os indivíduos agem para maximizar sua própria utilidade, fazendo lobby em normas de contabilidade com base no seu próprio interesse, e custos de agência surgem porque os interesses do gerente não coincidem necessariamente com os interesses dos acionistas, corroborando com a ideia anterior de maximização da sua própria utilidade (WATTS; ZIMMERMAN, 1979).

Em alguns estudos realizados, identificou-se que os sistemas de remuneração oferecidos aos executivos reduzem os problemas de agência gerados nas companhias. A remuneração dos executivos no Brasil é um sistema que alinha o comportamento das pessoas com os objetivos estratégicos do negócio (KRAUTER, 2013); afinal, empresas podem oferecer sistemas de incentivos como forma de atrelar a recompensa dos gestores ao desempenho econômico, reduzindo assim possíveis conflitos de agência (GONZAGA; YOSHINAGA; EID JUNIOR, 2014).

Outros estudos comentam que "[...] o projeto da remuneração dos executivos é visto não apenas como um instrumento para abordar o problema de agência entre gestores e acionistas, mas também como parte do próprio problema de agência" (BEBCHUK; FRIED, 2003, p. 1). Sendo assim, devem ser observados quais os fatores, dentro do próprio sistema de incentivo, que ajudam a minimizar e a agravar o conflito entre o principal e agente.

Em ambientes institucionais onde a "[...] propriedade está separada do controle, os gestores da corporação podem usar recursos corporativos para melhorar os seus interesses específicos e que tal uso pode não ser do interesse dos acionistas" (COUGHLAN; SCHMIDT, 1985, p. 43).

O plano de incentivo dos gestores chama atenção pela influência que tem sobre as escolhas contábeis das companhias. Após crises envolvendo grandes corporações mundiais como Enron e WordCom em 2001, e a crise do Subprime nos Estados Unidos em 2008, que envolveram grandes executivos, o Brasil passou a se preocupar com a regulamentação dos sistemas de remuneração dos diretores das companhias de capital aberto brasileiras. Em 2009, foi instituída a Instrução Normativa CVM n 480 , que entre as suas varias exigências, obrigou que as companhias brasileiras de capital aberto evidenciassem sua estrutura de remuneração e

REAd | Porto Alegre - Vol. 23 - No Especial - Dezembro 2017 - p. 4-28 
valores oferecidos aos diretores das companhias, exigindo a elaboração de um Formulário de Referência, que contenha todas as informações referentes às remunerações recebidas pelos administradores e diretores das companhias brasileiras de capital aberto.

Uma das formas de verificar se o plano de incentivo aos gestores está contribuindo também para minimizar o conflito de agência, é verificar se sua relação com o desempenho da companhia é positiva. Conforme Silva e Chien (2013), a remuneração baseada em desempenho auxilia a organização a atingir seus objetivos. Os estudos que abordam o sistema de remuneração das companhias com o desempenho financeiro são recorrentes na literatura, através da utilização de informações acerca dos rendimentos obtidos pelos gestores.

Estudos anteriores relacionaram com o desempenho das companhias proxies de remuneração, tais como: variáveis dummy na presença de remuneração variável, valores totais recebidos por executivos a título de remuneração ou variáveis contendo o quantitativo de cada espécie de remuneração recebida pelos executivos. Não há consistência nos resultados obtidos em estudos anteriores, pois alguns encontraram relação positiva entre remuneração e desempenho e outros não conseguiram encontrar tais evidencias, denotando assim, que não há um entendimento se os planos de remuneração aos gestores contribuem para o alinhamento de interesses entre principais e agentes, minimizando os conflitos de agência. O presente estudo se diferencia dos demais por utilizar outros métodos para definir a proxy remuneração executiva para relação com o desempenho das empresas. Serão utilizados os fatores financeiros e não financeiros que determinam a composição da remuneração dos gestores. Torna-se importante verificar a relação do desempenho com os determinantes da remuneração, pois fatores equivocados na determinação da remuneração do gestor podem ocasionar em uma falta de alinhamento de interesses entre as partes. A mudança do método na mensuração da remuneração dos executivos pode trazer resultados que contribuam na constituição de planos de remuneração que minimizem os problemas de agência, através dos fatores que medem o desempenho do executivo, e para os estudos posteriores sobre a temática.

Através da exposição da importância dos sistemas de remuneração dos gestores para as companhias e a forma que ele pode ser utilizado para obter melhor desempenho, o presente estudo objetiva verificar a relação dos determinantes da remuneração executiva com o desempenho financeiro e de mercado das companhias brasileiras de capital aberto listadas na BM\&FBovespa. O presente trabalho apresenta a seguinte hipótese genérica: os determinantes financeiros e não financeiros da remuneração executiva se relacionam de forma positiva e 
significativa com o desempenho financeiro e de mercado obtido pelas companhias brasileiras de capital aberto.

Este artigo é composto por mais quatro seções. A próxima seção apresenta a revisão da literatura sobre remuneração de executivos, teoria da agência e hipótese do plano de incentivos. A terceira seção é composta pelo método de coleta de dados, modelo estatístico e variáveis utilizadas. A quarta seção apresenta os resultados obtidos pela pesquisa. Finalmente, a última seção apresenta as conclusões do estudo, suas limitações e propostas para pesquisas futuras.

\section{REVISÃO DA LITERATURA}

A seguir é apresentada revisão de literatura sobre a teoria da agência e o estado da arte das pesquisas que abordaram sistemas de remuneração de gestores, para fundamentar a formulação das hipóteses.

\subsection{TEORIA DA AGÊNCIA E HIPÓTESE DO PLANO DE INCENTIVOS AOS GESTORES}

Jensen e Meckling (1976) definem uma relação de agência como sendo, um contrato onde uma ou mais pessoas empregam outra pessoa para realizar algum serviço ou trabalho em seu favor. O foco central dessa teoria está no relacionamento entre agente e principal, no qual o agente dispõe de informações privilegiadas e suas ações podem afetar o bem-estar entre as partes, sendo dificilmente observáveis pelo principal (LIMA; ARAÚJO; AMARAL, 2008, p. 149).

Conforme citado por Ghoshal (2005, p. 80), o modelo de agência produz algumas prescrições relativamente simples:

Expandir o número e a influência de conselheiros independentes em conselhos de administração para que eles possam efetivamente controlar a administração; dividir os papéis do presidente do conselho de administração e do diretor-presidente, a fim de reduzir o poder deste; criar mercados para o controle corporativo, isto é, para aquisições hostis, de modo que os invasores podem se livrar de gerentes de desperdício; e pagar gerentes com opções de ações para garantir que eles alcancem incansavelmente os interesses dos acionistas.

A teoria da agência fornece estrutura para o papel desempenhado pela Contabilidade 
no fornecimento de informações para avaliação, monitoramento e criação de mecanismos de incentivos (TEIXEIRA et al., 2011). Para Lima, Araújo e Amaral (2008, p. 150), “os mecanismos de controle devem então garantir que os gestores não tomem decisões conflitantes com o objetivo de maximizar o valor da empresa e, consequentemente das ações”. Conforme Ghoshal (2005, p. 75), "os interesses e incentivos dos gestores devem estar alinhados com os dos acionistas, por exemplo, fazendo das opções de ações uma parte significativa de seu salário".

Para Jensen e Meckling (1976), se ambas as partes da relação principal e agente forem maximizadoras de utilidade, existe razão para acreditar que o agente não irá atuar conforme os interesses do principal, assim surgindo o conflito da agência. Corroborando a esta afirmativa, Watts e Zimmerman (1979, p. 276) comentam que os "custos de agência surgem porque os interesses do gerente (os diretores) não coincidem necessariamente com os interesses dos acionistas ou obrigacionistas (os principais)". O conflito da agência ocorre quando o agente é contratado para agir de forma a maximizar a riqueza do principal, e acaba por perseguir seus próprios interesses, por isso, quando estabelecida à relação de agência, as decisões empreendidas tenderiam a ser conflituosas (MOURA et al., 2014).

A gestão representa os interesses dos acionistas, devendo tomar medidas que aumentem o valor do patrimônio da empresa, porém os gerentes muitas vezes têm seu próprio conjunto de interesses que afetam suas decisões e os interesses das partes (EISDORFER; GIACCOTTO; WHITE, 2013). A maioria dos acionistas de uma empresa podem vender suas ações mais facilmente do que a maioria dos gestores pode encontrar outro emprego, ou seja, em todos os sentidos substantivos, os gestores de uma empresa carregam mais riscos do que os acionistas (GHOSHAL, 2005).

Conforme apresentado, o grande risco que os gestores carregam, influencia no atendimento dos seus próprios objetivos, bem como as características do modelo da agência no plano de remuneração variável. Sendo assim, a teoria da agência “[...] pressupõe que as pessoas podem se comportar oportunisticamente, podendo induzir ações gerenciais que provavelmente aumentarão o comportamento oportunista entre as pessoas" (GHOSHAL, 2005, p. 77).

A teoria da agência, que está subjacente a todo edifício intelectual em apoio à maximização do valor para os acionistas, tem pouco poder explicativo ou preditivo (GHOSHAL, 2005, p. 80). Ou seja, a teoria da agência e seus efeitos sobre a governança corporativa têm evidencias não confirmatórias e prescrições ineficazes, pois a teoria não 
cederia prontamente a proposições firmes e testáveis e nem proporcionaria receitas simples e reducionistas (PFEFFER, 2005).

Nas grandes propriedades de capital aberto, onde a propriedade é separada da gestão, o conselho de administração é o maior meio de influência dos acionistas sobre os executivos. Assim sendo, os teóricos da agência comentam que para minimizar os conflitos de agência nessas grandes companhias abertas, pode ser aumentado o número de outsiders, com participação acionária significativa na empresa e que não tenham sido nomeados pelo CEO (HAMBRICK; FINKELSTEIN; MOONEY, 2005).

Também, com o objetivo de alcançar uma harmonia na relação entre os principais e agentes “[...] as empresas utilizam mecanismos de incentivos para alinhamento de interesses, buscando influenciar o comportamento dos agentes de modo a alcançarem o nível de desempenho desejado pelos proprietários do capital" (GONZAGA; YOSHINAGA; EID JUNIOR, 2013, p.106).

Coughlan e Schmidt (1985) realizaram um estudo que objetivou investigar os mecanismos internos de controle gerencial à disposição do conselho ou comitê de definição de compensação dos executivos. Os resultados da pesquisa identificaram que a diretoria da empresa cria incentivos gerenciais compatíveis com dos proprietários da empresa, com a criação de um plano de incentivos que beneficia também os interesses dos acionistas.

Nesse contexto, Bebchuk e Fried (2003) comentam que muita investigação tem se voltada para uma forma de compensação de executivos que ajude a minimizar o problema da agência em empresas de capital aberto, porém é necessário reconhecer que a concepção de sistemas de remuneração é também, em parte, produto do mesmo problema da agência.

Para Bezerra et al. (2012), os gestores das organizações, que recebem planos de bonificação baseados no lucro são mais propensos a escolher procedimentos contábeis que façam com que os lucros futuros sejam reportados no período presente, sugerindo que o comportamento de um gestor é direcionado a maximizar seus ganhos. Porém, Chen e Ma (2011) afirmam que compensações de executivos baseados ações ou em opções de ações, são considerados muito eficazes para reduzir os problemas de agência corporativa.

Os executivos de grandes companhias geralmente ganham altos salários e têm reputações, por estes motivos, os executivos estão suscetíveis a se envolver em operações ilegais com insider trading, o que pode prejudicar os interesses dos principais (ORDU; SCHWEIZER, 2015).

Muitas companhias adotam indicadores contábeis na determinação dos sistemas de 
remuneração. Os sistemas que são atrelados a números contábeis, satisfazem os objetivos do principal no curto prazo, prejudicando assim a visão de longo prazo dos mesmos (FARREL; KADOUS; TOWRY, 2008).

Os gestores cuja compensação é dependente dos resultados, por meio de planos de compensação, acabam sendo induzidos a suavizar as medidas de desempenho (SUNDER, 2014). Ou seja, os “contratos que usam números contábeis não são eficazes no alinhamento de interesses e gestores [...]" (WATTS; ZIMMERMAN, 1990, p.118).

Quando um sistema de incentivos aos gestores é mal elaborado ou baseado em indicadores que prejudicam a visão do principal, o sistema de remuneração tende a fazer parte do problema da agência (BEBCHUK; SPAMANN, 2010). O plano de remuneração deve alinhar os objetivos das partes do contrato, sendo bem estruturado e baseado em indicadores que se relacionem com o desempenho futuro da empresa.

Um plano de incentivo baseados em fatores não ligados ao resultado da companhia (por exemplo, qualidade) tende a alinhar melhor os interesses das partes, pois costumam ser os principais indicadores do desempenho futuro da empresa (FARREL; KADOUS; TOWRY, 2008), ou seja, um plano de remuneração ligado a indicadores não financeiros e orientados para o longo prazo das companhias, pode minimizar os conflitos de agência, alinhando os objetivos dos executivos aos dos acionistas.

Corroborando a ideia anterior, Sauset, Waller e Wolff (2015, p. 685) comentam que a experiência recente em relação à crise financeira, tem mostrado que "[...] as estruturas de remuneração têm se tornado cada vez mais complexas, concentradas em resultados em curto prazo e, em alguns casos, levou a uma remuneração excessiva, o que não era justificado pelo desempenho $[\ldots]$ ".."

Com o objetivo de fornecer um melhor entendimento sobre as práticas de remuneração dos gestores, o próximo item desta seção retrata como estudos e normas abordam a composição do plano de remuneração dos executivos.

\subsection{ESTRUTURA DO PLANO DE INCENTIVO AOS GESTORES}

A remuneração dos executivos é um dos sistemas mais importantes da administração de empresas. Para Beuren, Kaveski e Rigo (2014), a remuneração pode ser considerada uma das principais, e para muitos a principal variável na relação de trabalho entre empregador e empregado. Uma das formas de tornar as empresas mais competitivas e com maior excelência 
nos seus processos está na preocupação com seus funcionários, e a remuneração é uma maneira de explicitar essa preocupação, sendo que a melhor remuneração tende a gerar bemestar, motivação para o alcance de objetivos, e maior comprometimento com o negócio (NUNES, 2008).

No estudo realizado por Jensen, Murphy e Wruck (2004, p.19) afirma-se que:

\begin{abstract}
Um pacote de remuneração bem concebido para executivos (ou para os funcionários em todos os níveis da organização) irá realizar três coisas: atrair os executivos certos ao menor custo; reter os executivos certos ao menor custo (e incentivar os executivos certos para deixar a empresa no momento apropriado); e motivar os executivos a tomar medidas que criam valor para os acionistas a longo prazo.
\end{abstract}

Conforme citado por Oliva e Albuquerque (2007), quando a questão da remuneração é tratada no âmbito dos executivos das empresas, a complexidade é maior ainda porque se trata de um grupo com alta concentração de poder e que geralmente não se submete às mesmas políticas de recursos humanos destinadas aos demais funcionários da organização. As empresas utilizam mecanismos de incentivos para alinhamento de interesses, buscando influenciar o comportamento dos agentes de modo a alcançarem o nível de desempenho desejado pelos proprietários de capital (GONZAGA; YOSHINAGA; EID JUNIOR, 2013).

Segundo Souza e Borba (2007), é importante que a empresa tenha um procedimento formal e transparente para desenvolver sua política de remuneração, por este motivo, nenhum diretor deve estar envolvido nesse processo, uma vez que abrange sua própria remuneração.

No Brasil, a Instrução CVM n ${ }^{\circ}$ 480/2009 regulamenta a evidenciação da remuneração dos executivos. Nessa Instrução Normativa, a seção 13 do anexo 24 (Conteúdo do Formulário de Referência), estabelece as informações referentes à remuneração dos executivos que devem ser evidenciadas, objetivando a transparência nas divulgações relativas aos participantes do mercado de capitais (CVM, 2009). Beuren, Mazzioni e Silva (2014) definem o Formulário de Referência como um documento periódico, de publicação obrigatória, que reúne informações relevantes para a compreensão e a avaliação de uma empresa, originadas de suas diferentes áreas internas. A estrutura de remuneração imposta pela CVM, resumidamente é composta por remuneração fixa, remuneração variável e remuneração baseada em ações. Já para Machado e Beuren (2013) os planos de remuneração de executivos podem conter quatro componentes básicos: salário-base, bônus anual vinculado ao desempenho contábil ou a outro indicador acordado entre as partes, opções de ações e planos de incentivos de longo prazo.

A proposta de um plano de remuneração dos gestores, apresentada por Watts e REAd | Porto Alegre - Vol. 23 - No Especial - Dezembro 2017 - p. 4-28 
Zimmerman (1978, p. 114), consiste em "salários, remuneração de incentivo (bônus em dinheiro e ações ou opções), e receitas não pecuniárias, incluindo gratificações”. Percebe-se a inclusão de remuneração fixa e variável, tanto de curto e longo prazo, o que satisfaz um plano de remuneração diversificado para as companhias.

Para Raviv e Sisli-Ciamarra (2013, p. 55), após a crise financeira mundial de 2007, as "[...] grandes organizações bancárias foram convidadas a reconsiderar suas práticas de remuneração de executivos com base na visão de que as práticas de incentivo no setor financeiro foram um dos muitos fatores que contribuíram para a crise". Na Alemanha, os escândalos corporativos tiveram forte impacto em vários aspectos de governança corporativa, incluindo a divulgação e os sistemas de compensação de executivos. A lei da divulgação da remuneração de diretores tem obrigado as empresas a evidenciarem desde 2006, a remuneração total dos membros executivos, segregados em: salário fixo; bônus de curto prazo e incentivos de longo prazo (HITZ; MÜLLER-BLOCH, 2015).

Porém para Sauset, Waller e Wolff (2015), a crise resultou em um conjunto de princípios de design de contrato que recomenda que as empresas de toda a Europa incorporem uma série de elementos em contratos de remuneração de gestores, como: orientações acionárias, diferimento de bônus, recuperações de custo, predeterminantes, metas de desempenho mensuráveis para bônus e subvenções de capital.

Através do exposto, vale destacar a importância da remuneração de longo prazo na estrutura de remuneração, pela sua função no alinhamento de interesses. Bebchuk e Fried (2003, p. 13) salientam seu "forte apoio para a compensação baseada em ações, que, em princípio, pode fornecer aos gestores com incentivos muito desejáveis". Para Eisdorfer, Giaccotto e White (2013, p. 550) "um pacote típico de remuneração dos gestores pode ser visto como uma carteira de uma dívida como componente (pensão e compensação diferida), e um capital próprio como componente (ações e opção de ações)".

Um esquema resumido do plano de remuneração foi elaborado por Krauter (2013, p.261), ele trata a remuneração em aspectos distintos dos demais, foi incluído um fator chamado de remuneração não financeira.

Ao verificar a composição da estrutura da remuneração dos executivos, destaca-se que como forma de alinhamento de interesses, Chen e Ma (2011, p. 641) comentam que "[...] se a remuneração não está relacionada com o desempenho da empresa, há pouco incentivo para que os gestores tomem projetos de investimentos de risco", assim afetando futuros ganhos para a empresa.

REAd | Porto Alegre - Vol. 23 - No Especial - Dezembro 2017 - p. 4-28 
Figura 1 - O conceito de remuneração

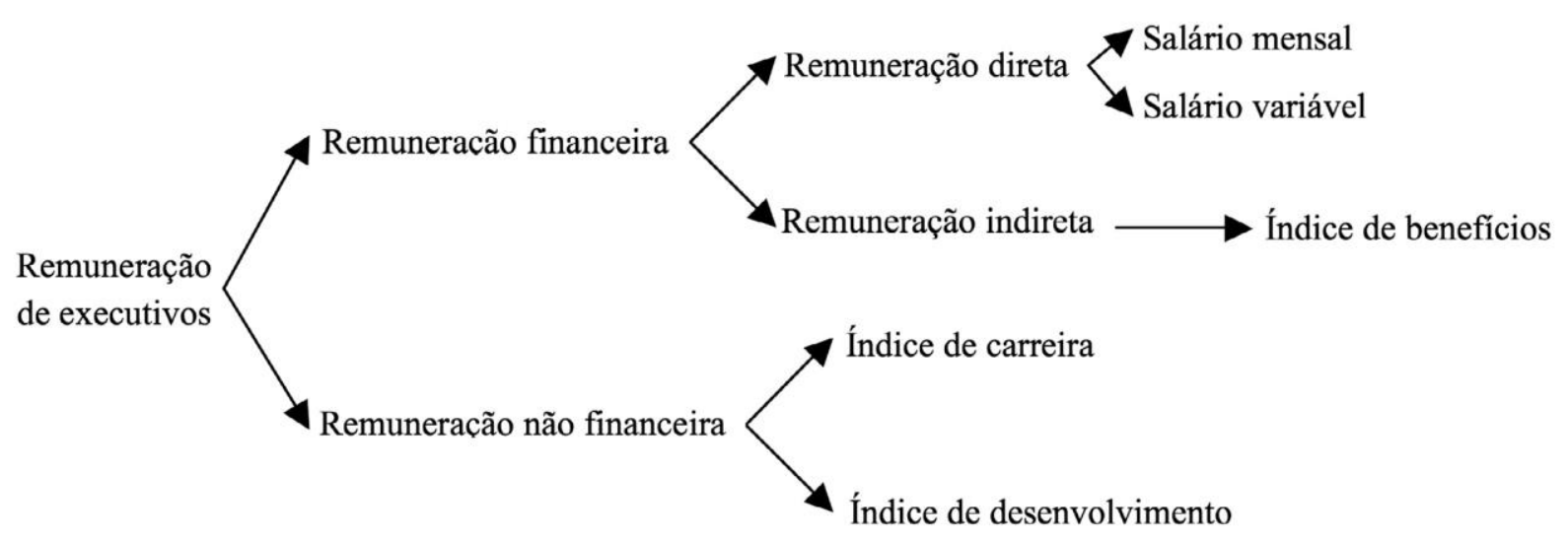

Fonte: Krauter (2013, p.261).

\subsection{REMUNERAÇÃO E DESEMPENHO FINANCEIRO NO BRASIL}

Ao avaliar o desempenho financeiro das empresas, muitos fatores devem ser levados em consideração. Ribeiro, Macedo e Marques (2012) comentam que existem muitas medidas para a avaliação do desempenho das companhias, porém com a dificuldade de identificar qual a estrutura ideal de uma medida de desempenho das organizações. A presente pesquisa se baseia nos indicadores de desempenho financeiro, utilizados em pesquisas que fizeram a relação entre planos de remuneração e desempenho financeiro.

A pesquisa de Camargos e Helal (2007) teve como objetivo, realizar uma análise das variáveis de desempenho e governança que explicam a remuneração de executivos de empresas brasileiras que tem American Depositary Receipts (ADR). Foram utilizados como variáveis de desempenho financeiro: a razão do índice de valor de mercado e valor contábil; o retorno acionário; lucro por ação; retorno sobre os ativos e retorno sobre o patrimônio líquido. Os resultados encontrados apontam para uma relação entre remuneração executiva e desempenho financeiro das empresas, sendo identificado que os pacotes de compensação dos executivos estão diretamente associados ao bom desempenho das empresas brasileiras.

Em outro estudo, Nascimento, Franco e Cherobim (2012) objetivaram verificar se existe associação entre os índices contábeis financeiros e as práticas de remuneração variável nas empresas do setor de energia elétrica do Brasil. As variáveis de desempenho utilizadas foram: margem líquida; taxa de retorno sobre o ativo total; retorno sobre o patrimônio líquido; e o lucro disponível ao acionista. Os resultados da pesquisa constatam que as práticas de remuneração variável não têm influência positiva nos resultados dos índices de lucratividade e rentabilidade das empresas do setor elétrico brasileiro.

REAd | Porto Alegre - Vol. 23 - No Especial - Dezembro 2017 - p. 4-28 
Na pesquisa realizada por Gonzaga, Yoshinaga e Eid Junior (2013), foi verificado que a existência de relação entre incentivos gerenciais oferecidos aos gestores com o desempenho das empresas brasileiras. Como medida de desempenho contábil, foi utilizado o retorno sobre o patrimônio líquido. Os resultados apontam para evidências na relação entre incentivos gerenciais e o desempenho econômico das empresas.

Krauter (2013) objetivou investigar a relação entre a remuneração dos executivos e o desempenho financeiro nas empresas brasileiras. Foram utilizados como indicadores de desempenho contábil: o retorno sobre os ativos e o retorno sobre o patrimônio líquido. Os resultados apontam que existe relação entre remuneração financeira e desempenho financeiro e entre remuneração não financeira e desempenho financeiro.

A pesquisa de Silva e Chien (2013) objetivou identificar se a remuneração dos executivos afeta o valor e desempenho das empresas no Brasil. Foi utilizado apenas o retorno sobre os ativos, como medida de desempenho. O resultado dessa pesquisa constatou que não existe relação significativa entre remuneração executiva, valor e desempenho da empresa.

Beuren, Mazzioni e Silva (2014) analisaram se a remuneração dos executivos está correlacionada com o tamanho e o desempenho das empresas brasileiras de capital aberto. Os indicadores utilizados para avaliar o desempenho financeiro das companhias foram: retorno sobre os ativos; lucro por ação e dividendo por ação. Os resultados confirmam a ocorrência de relação entre remuneração dos executivos e desempenho de mercado das empresas pesquisadas, porém surpreendem pela não ocorrência de relação com os indicadores financeiros.

A pesquisa realizada por Souza e Farias (2015), objetivou verificar a relação existente entre a remuneração dos executivos e o desempenho financeiro das companhias abertas do Brasil. As variáveis de desempenho utilizadas foram o retorno sobre os ativos e o retorno sobre o patrimônio líquido, sendo que as variáveis de remuneração de curto prazo apresentaram-se positivamente relacionadas com indicadores de desempenho financeiro das companhias, porém para a remuneração baseada em ações (de longo prazo), o modelo estatístico evidenciou uma relação negativa com o desempenho das companhias.

Após o levantamento dos pilares teóricos que abordam o tema não se identificou a utilização de proxies que determinam a remuneração dos executivos nas empresas brasileiras de capital aberto, sendo este o diferencial do presente estudo.

\section{MÉTODO}

REAd | Porto Alegre - Vol. 23 - No Especial - Dezembro 2017 - p. 4-28 
Esta seção visa abordar os procedimentos adotados para a coleta dos dados, o modelo estatístico utilizado no teste da hipótese e as variáveis utilizadas no modelo de regressão adotado.

\subsection{PROCEDIMENTOS PARA A COLETA DE DADOS}

Foram selecionadas as empresas de capital aberto listadas na BM\&FBovespa, de acordo com a relação disponibilizada pela Comissão de Valores Mobiliários. É importante utilizar companhias de capital aberto pela obrigatoriedade de evidenciarem informações, dentre elas, as informações referentes à remuneração dos executivos.

Em acesso ao site da CVM, foram encontradas 611 empresas ativas. Foram excluídas 378 por alguma das seguintes razões: não conterem informações referentes à remuneração; ausência de formulários; não obrigatoriedade de publicação das informações; não adotarem política de remuneração; ou não se repetirem nos três anos da análise. O número final de empresas contidas na amostra foi de 228.

Como a Instrução CVM 480/2009 obrigou as companhias a evidenciarem informações sobre as remunerações, foram escolhidos os anos de 2011 a 2013, por esses períodos já compreenderem as informações de forma completa pelas companhias selecionadas. Esse período é um dos mais atuais se relacionados às pesquisas anteriores sobre remuneração.

As informações sobre a remuneração se referem aos pagamentos realizados para os diretores, vice-presidentes e presidentes, os quais nesse trabalho denominam-se "executivos". Estão contidas nos formulários de referência da CVM as informações sobre a remuneração de diretores, administradores, comitê fiscal, comitê de auditoria entre outros. Porém, a coleta de dados foi feita apenas com ênfase na remuneração da diretoria, que denota maior número de remunerações variáveis.

\subsection{MÉTODOS QUANTITATIVOS EMPREGADOS NO ESTUDO}

Para testar a relação entre remuneração dos executivos com o desempenho financeiro das empresas brasileiras de capital aberto foi utilizado o teste de regressão múltipla linear, em painéis com estimativas de efeitos fixos. Foram utilizadas como variáveis dependentes o Retorno sobre os Ativos (ROA), o Retorno sobre o Patrimônio Líquido (ROE) e a Variação das Ações (VA), ambos defasados em um ano (i.e., $\mathrm{t}+1$ ). As pesquisas realizadas por 
Camargos e Helal (2007); Silva e Chien (2013); Krauter (2013); Beuren, Mazzioni e Silva (2014) e Souza e Farias (2015) utilizaram como medida de desempenho financeiro o ROA, enquanto as pesquisas realizadas por Camargos e Helal (2007); Nascimento, Franco e Cherobim (2012); Krauter (2013); Gonzaga, Yoshinaga e Eid Junior (2013) e Souza e Farias (2015) utilizaram o ROE como medida de desempenho financeiro. Nas pesquisas realizadas por Camargo e Helal (2007) e Silva e Chien (2013), foram utilizadas variáveis que avaliam o desempenho do mercado, sendo em nossa pesquisa empregada a variável Variação das Ações (VA) para avaliar este desempenho. Percebe-se que por maioria as pesquisas utilizam ROA ou ROE como proxy de desempenho financeiro.

O objetivo da utilização da variável de desempenho em $\mathrm{t}+1$ é testar se as variáveis independentes estão relacionadas com o desempenho no futuro, e não apenas atenderem a visão dos acionistas no curto prazo. Como variáveis independentes foram utilizadas: a dummy da utilização de Remuneração Baseada em Indicadores Financeiros (RBIF), medidos pela utilização de apenas fatores financeiros pelas companhias na determinação da remuneração dos gestores, a dummy da utilização Remuneração Baseada em Indicadores Não Financeiros (RBINF), medidos pela utilização de apenas fatores não financeiros pelas companhias na determinação da remuneração dos gestores, a dummy de Remuneração Baseada em Indicadores Financeiros e Não Financeiros (RBIF\&NF), medidos pela utilização de fatores financeiros e não financeiros, simultaneamente pelas companhias na determinação da remuneração dos gestores, e o Retorno sobre os Ativos (ROA) e Retorno sobre o Patrimônio Líquido (ROE) no período t. As variáveis de controle utilizadas no modelo estatístico foram: Tamanho das empresas, medidos pelo total de ativos da companhia (AT), Índice de Liquidez Geral (LG) e Grau de Endividamento das Companhias (END).

O modelo de regressão utilizado testa as hipóteses de relação positiva e significativa entre Remuneração dos Executivos e Desempenho Financeiro das companhias mediante duas versões. Em uma o desempenho financeiro é medido com base no retorno sobre o ativo (ROA), equação 1; na outra o desempenho financeiro é medido com base no retorno sobre o patrimônio líquido (ROE), equação 2; e o desempenho de mercado é medido com base no índice de variação das ações (VA), equação 3, conforme demonstrado a seguir:

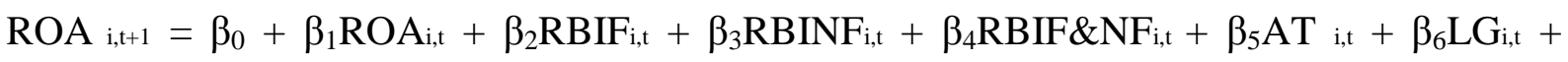
$\beta_{7} \mathrm{END}_{\mathrm{i}, \mathrm{t}}+\mu_{\mathrm{i}, \mathrm{t}}$ 


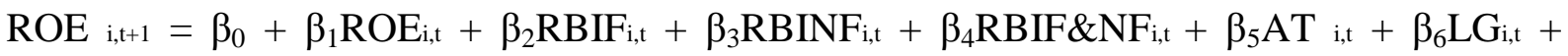
$\beta_{7} \mathrm{END}_{\mathrm{i}, \mathrm{t}}+\mu_{\mathrm{i}, \mathrm{t}}$

Equação 2

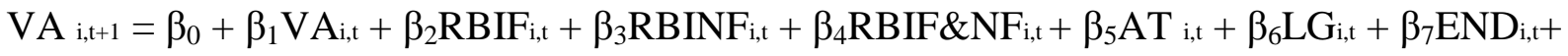
$\mu_{\mathrm{i}, \mathrm{t}}$

Equação 3

Para as análises estatísticas de regressão foi utilizado o software GRETL®, o qual viabilizou a análise dos dados por meios de painéis. Foram extraídas da base de dados ECONOMÁTICA® informações referentes ao Total de Ativos, Total do Patrimônio Líquido, Lucro Liquido, Passivo Circulante e Passivo Não Circulante. Essas informações foram essenciais para calculo dos indicadores: Retorno sobre os Ativos (ROA); Retorno sobre o Patrimônio Líquido (ROE); Liquidez Geral (LG) e Grau de Endividamento (END).

\section{RESULTADOS DA PESQUISA}

Primeiramente, serão evidenciados os fatores financeiros e não financeiros observados na análise dos formulários de referencia da CVM, que foram utilizados na construção das variáveis dummy de remuneração adotadas no modelo estatístico. Após a evidenciação dos fatores determinantes da remuneração, serão evidenciados os modelos em painéis adotados no teste de regressão linear múltipla que visam verificar se o desempenho financeiro das companhias está relacionado com os sistemas de remuneração dos seus gestores.

\subsection{FATORES DETERMINANTES DA REMUNERAÇÃO EXECUTIVA}

O estudo verificou quais os indicadores são utilizados na determinação da remuneração dos executivos das companhias de capital aberto do Brasil. O anexo 13.1 do formulário de referência exigido pela CVM, objetiva descrever a política ou a prática de remuneração dos executivos.

Para operacionalizar as variáveis de remuneração, identificaram-se quais os fatores determinantes da remuneração dos executivos, através da afirmativa de Watts e Zimmerman (1990, p. 118), de que "contratos que usam números contábeis não são eficazes no alinhamento de interesses e gestores [...]". 
O item c do formulário de referência 13.1 descreve os principais indicadores de desempenho na determinação de cada elemento da remuneração, sendo esta a principal fonte dos dados sobre a remuneração dos gestores das companhias abertas brasileiras.

Ao verificar os formulários de referência de 228 empresas de capital aberto, identificou-se um número total de 31 indicadores financeiros, adotados na determinação dos elementos de remuneração dessas companhias conforme o Quadro 1.

Quadro 1 - Indicadores de desempenho financeiro utilizados na determinação da remuneração dos executivos

\begin{tabular}{|ll|}
\hline FATORES FINANCEIROS DETERMINANTES DA REMUNERAÇÃO \\
\hline Análise Mercado Financeiro & Lucro Líquido após Impostos \\
Custos De Produção & Margem De Contribuição \\
Despesa De Pessoal & Margem liquida \\
Despesa Total & PDD + Incobráveis \\
Despesas Controláveis & Perdas \\
Dividendos & Preço De Marcado Das Ações \\
EBIT & Receita Bruta \\
EBITIDA & Receita Líquida \\
EVA & Resultado Operacional \\
Fluxo De Caixa & Resultados Financeiros \\
Geração De Caixa Operacional & Resultados Operacionais \\
Índice De Endividamento & ROE \\
LAIR & ROA \\
Liquidez Corrente & Valor De Mercado Da Empresa \\
Liquidez Geral & Variação Do Capital De Giro \\
Lucro Líquido & Volume De Vendas \\
\hline
\end{tabular}

Fonte: Dados da Pesquisa.

Além dos indicadores de desempenho financeiro, foram encontrados 36 indicadores não financeiros na determinação da remuneração das companhias conforme o Quadro 2.

Foram utilizadas no modelo de regressão 228 empresas encontradas na pesquisa, utilizando com base os dados dos três anos de análise. Dessas, 39 empresas não adotam indicadores para determinar sua estrutura de remuneração, por terem apenas remunerações fixas ou motivos não explicitados; 116 empresas que utilizam indicadores financeiros na determinação dos elementos da remuneração; 23 empresas que utilizam apenas indicadores não financeiros na determinação dos elementos de remuneração das companhias; e por fim, 50 empresas, utilizam tanto indicadores financeiros, quanto indicadores não financeiros na 
determinação dos elementos da remuneração dos executivos destas companhias.

Todas essas observações foram essências para a constituição de variáveis dummy utilizadas no modelo de regressão linear múltipla.

A próxima subseção evidencia a análise dos dados com os respectivos resultados, através dos modelos de regressão em painéis testados, incluindo as variáveis dummy encontradas e outras variáveis testadas, de acordo com o modelo estatístico proposto.

Quadro 2 - Indicadores de desempenho não financeiro utilizados na determinação da remuneração dos executivos

\begin{tabular}{|ll|}
\hline \multicolumn{2}{|c|}{ FATORES NÃO FINANCEIROS DETERMINANTES DA REMUNERAÇÃO } \\
\hline Produção de Óleo e Gás & Captação de Recursos \\
Obras de Terceiros & Vendas Remanescentes \\
Eficiência & Avaliação Individual \\
Volume de Lançamentos & Segurança no Trabalho \\
Pessoas & Foco Estratégico \\
Volume de Obras Executadas & Qualidade \\
Avaliação CGPAR & Expansão dos Negócios \\
Avaliação do Clima Organizacional & Particip. Mercado Internacional \\
Orçamento & Particip. Mercado Nacional \\
Projetos Socioambientais & Empenho \\
Comprometimento & Sinistros com Cargas/Embarcações \\
Produtividade & Compra de Landback \\
Aplicação em Crédito Comercial & Competência \\
Gestão por Desempenho & Plano de Investimento \\
Satisfação do Cliente & Material Empregado \\
Working de Capital & Inadimplência \\
Comprimento de Metas & Conclusão de Projetos \\
Qualidade do Credito & Processamento Petróleo Nacional \\
\hline
\end{tabular}

Fonte: Dados da pesquisa.

\subsection{ANÁLISE DOS DADOS DA PESQUISA}

Com o objetivo de verificar a relação do desempenho das companhias com os sistemas de remuneração dos executivos, é necessário testar a hipótese de relação através do modelo de regressão linear múltipla. Foi adotado o modelo de regressão em painéis, sendo feitas análises através dos efeitos fixos. 
Foram utilizados três modelos em painéis, sendo o primeiro e segundo com a utilização do índice ROA e ROE para medir desempenho financeiro e o terceiro, com a utilização do índice VA para medir o desempenho de mercado, ambos utilizam estas variáveis tanto no período $t$, quanto no período $t+1$.

O primeiro modelo de regressão linear múltipla adotou ROA como índice de desempenho financeiro e variável dependente. Foram utilizadas 228 empresas com um total de 684 observações no modelo testado, através de painel com efeitos fixos. A Tabela 1 evidencia o modelo em painel com dados para os anos de 2011 a 2013. O índice ROA em t+1, utilizou o ROA do ano de 2014.

Tabela 1- Regressão linear múltipla em painel - Variável Dependente (ROA em t+1)

\begin{tabular}{lccccc}
\hline & COEFICIENTE & ERRO PADRÃO & RAZÃO-T & P-VALOR & \\
\hline Constante & $-11,2826$ & 22,8341 & $-0,4941$ & 0,6215 & \\
ROA $_{\mathrm{t}}$ & $-0,353276$ & 0,130967 & $-2,6974$ & 0,0073 & $* * *$ \\
RBIF & 0,223309 & 0,139181 & 1,6044 & 0,1093 & \\
RBINF & 0,334642 & 0,28789 & 1,1624 & 0,2457 & \\
RBIF\&NF & 0,876585 & 0,214206 & 4,0923 & $<0,0001$ & $* * *$ \\
AT & 3,59788 & 3,50788 & 1,0257 & 0,3056 & \\
LG & $-3,0338$ & 1,12005 & $-2,7086$ & 0,0070 & $* * *$ \\
END & $-10,7613$ & 5,30121 & $-2,0300$ & 0,0429 & $* *$ \\
\hline
\end{tabular}

ROA = Retorno sobre os Ativos; RBIF = Remuneração Baseada em Indicadores Financeiros; RBINF = Remuneração Baseada em Indicadores Não Financeiros; RBIF\&NF = Remuneração Baseada em Indicadores Financeiros e Não Financeiros; AT = Tamanho da Empresa; LG = Liquidez Geral da Empresa; END = Endividamento das Empresas.

***, ** e * correspondem à significância estatística nos níveis de $1 \%, 5 \%$ e 10\%, respectivamente.

Fonte: elaborado pelos autores.

Os resultados deste modelo confirmam a hipótese de uma relação positiva e significativa entre o desempenho financeiro, medido através do ROA em $t+1$, com uma, das três variáveis dummy observadas. Há uma forte significância na relação da Remuneração Baseada em Indicadores Financeiros e Não Financeiros (RBIF\&NF), com o desempenho financeiro, também ao nível de $1 \%$ de significância. Vale ressaltar que a variável está relacionada positivamente com o desempenho financeiro medido através do ROA.

A variável de controle Liquidez Geral (LG) e Endividamento (END) se mostraram significativas com o ROA ao nível de 5\%, porém ambas de forma negativa. O R-quadrado deste modelo de regressão em painel foi de 0,7264 , ou seja, há $72,64 \%$ de confiabilidade no modelo de regressão testado. 
O segundo modelo de regressão linear múltipla adotou o ROE como índice de desempenho financeiro e variável dependente. Foram utilizadas 228 empresas com um total de 684 observações no modelo testado, através de painel com efeitos fixos. A Tabela 2 evidencia o modelo em painel com dados para os anos de 2011 a 2013. O índice ROE em t+1 utilizou o ROE do ano de 2014.

O modelo em painel com a utilização do ROE como indicador de desempenho evidencia que apenas a variável dummy de Remuneração Baseada em Indicadores Não Financeiros (RBINF) mostrou-se relacionada com o desempenho financeiro (ROE) de forma positiva, com forte significância ao nível de 1\%. Este resultado difere dos resultados do modelo anterior, onde houve relação positiva e significativa com o RBIF\&NF.

Tabela 2 - Regressão linear múltipla em painel - Variável Dependente (ROE em t+1)

\begin{tabular}{lcccc}
\hline & COEFICIENTE & ERRO PADRÃO & RAZÃO-T & \multicolumn{2}{c}{ P-VALOR } \\
\hline Constante & 960,59 & 944,665 & 1,0169 & 0,3098 \\
ROE $_{\mathrm{t}}$ & $-0,389694$ & 0,125573 & $-3,1033$ & 0,0020 \\
RBIF & $-0,0900529$ & 0,142645 & $-0,6313$ & 0,5282 \\
RBINF & 10,3887 & 1,16554 & 8,9132 & $<0,0001$ \\
RBIF\&NF & $-0,699274$ & 1,46231 & $-0,4782$ & 0,6327 \\
AT & $-160,62$ & 140,644 & $-1,1420$ & 0,2540 \\
LG & 19,136 & 48,1211 & 0,3977 & 0,6911 \\
END & 96,3729 & 190,698 & 0,5054 & 0,6135
\end{tabular}

ROE = Retorno sobre o Patrimônio Líquido; RBIF = Remuneração Baseada em Indicadores Financeiros; RBINF = Remuneração Baseada em Indicadores Não Financeiros; RBIF\&NF = Remuneração Baseada em Indicadores Financeiros e Não Financeiros; AT = Tamanho da Empresa; LG = Liquidez Geral da Empresa; END = Endividamento das Empresas.

$* * *, * * \mathrm{e} *$ correspondem à significância estatística nos níveis de $1 \%, 5 \%$ e $10 \%$, respectivamente.

Fonte: elaborado pelos autores.

As demais variáveis testadas, tanto as independentes, quanto as de controle, não foram significantes na sua relação com o desempenho em $t+1$ medido através do ROE. O Rquadrado do modelo testado foi de 0,5047 , ou seja, a confiabilidade ou poder de explicação do modelo é de 50,47\%.

O terceiro modelo de regressão linear múltipla adotou a VA como índice de desempenho de mercado e variável dependente. Foram utilizadas 192 empresas, a Tabela 3 evidencia o modelo em painel com dados para os anos de 2011 a 2013. O índice VA em t+1 utilizou a variação das ações do ano de 2014. 
Tabela 3 - Regressão linear múltipla em painel - Variável Dependente (VA em t+1)

\begin{tabular}{lcccc}
\hline & COEFICIENTE & ERRO PADRÃO & RAZÃO-T & P-VALOR \\
\hline Constante & 12,7347 & 14,7853 & 0,8613 & 0,3896 \\
VA $_{\mathrm{t}}$ & $-0,276675$ & 0,930303 & $-0,2974$ & 0,7663 \\
RBIF & $-0,226007$ & 0,93355 & $-0,2421$ & 0,8088 \\
RBINF & 0,276613 & 0,930301 & 0,2973 & 0,7664 \\
RBIF\&NF & $-0,217193$ & 0,931789 & $-0,2331$ & 0,8158 \\
AT & $-2,17202$ & 2,28311 & $-0,9513$ & 0,3420 \\
LG & 2,86242 & 3,42906 & 0,8348 & 0,4044 \\
END & 0,166721 & 0,650563 & 0,2563 & 0,7979 \\
\hline
\end{tabular}

VA = Variação Acionária; RBIF = Remuneração Baseada em Indicadores Financeiros; RBINF = Remuneração Baseada em Indicadores Não Financeiros; RBIF\&NF = Remuneração Baseada em Indicadores Financeiros e Não Financeiros; AT = Tamanho da Empresa; LG = Liquidez Geral da Empresa; END = Endividamento das Empresas.

***, ** e * correspondem à significância estatística nos níveis de $1 \%, 5 \%$ e $10 \%$, respectivamente. Fonte: elaborado pelos autores.

O modelo em painel com a utilização do VA como indicador de desempenho não alcançou nenhum nível de significância entre as variáveis utilizadas no modelo de regressão. O R-quadrado do modelo testado foi de 0,5037, ou seja, a confiabilidade ou poder de explicação do modelo é de 50,37\%.

\subsection{RESULTADOS ALCANÇADOS PELA PESQUISA}

A primeira regressão, que utiliza o ROA como variável de desempenho evidencia que um plano de remuneração misto, baseado em indicadores financeiros e não financeiros (RBIF\&NF) tende a alinhar de forma mais eficaz os interesses entre o principal e agente, através da relação positiva e significativa ao nível de $1 \%$ entre os indicadores. Na segunda regressão, que utilizou o ROE como indicador de desempenho, obteve resultado positivo e significativo ao nível de 1\% com o indicador de Remuneração Baseada em Indicadores NãoFinanceiros (RBINF). Os resultados alcançados por estes dois modelos estatísticos testados evidenciam que as remunerações baseadas em indicadores financeiros não alinham os interesses dos gestores aos dos acionistas, pois em nenhum dos dois modelos houve relação positiva e significativa com as variáveis dummy de Remuneração Baseada em Indicadores Financeiros (RBIF).

Os resultados estão de acordo com Watts e Zimmerman (1990), que afirmaram em seu estudo que os contratos que usam números contábeis, ou seja, indicadores financeiros, não são eficazes no alinhamento de interesses do agente aos do principal. Os resultados estão de acordo também com Farrel, Kadous e Towry (2008), que afirmaram que medidas de 
desempenho não financeiras podem ser os principais indicadores do futuro desempenho da empresa.

Por outro lado, os resultados da terceira e última regressão, onde foi utilizado como indicador de desempenho a Variação das Ações (VA), não houve relações significativas com as dummies dos determinantes da remuneração dos executivos. Este resultado evidencia falta de alinhamento de interesses entre as partes do contrato de agência, pois o valor do acionista não acompanha a remuneração executiva.

\section{CONSIDERAÇÕES FINAIS}

O sistema de remuneração dos executivos é compreendido como uma das ferramentas para minimizar o problema da agência, que ocorre quando os objetivos do agente vão de encontro com os objetivos do principal. O presente estudo objetivou verificar a relação existente entre os determinantes da remuneração executiva, com o desempenho financeiro e de mercado das companhias brasileiras de capital aberto com ações negociadas na BM\&FBovespa. A pesquisa contou com uma amostra de 228 empresas, com 684 observações entre os anos de 2011 a 2013.

Foram utilizados três modelos de regressão linear múltipla em painéis com efeitos fixos, para testar a hipótese de uma relação positiva e significativa entre o desempenho financeiro e o sistema de remuneração de executivos, das companhias abertas do Brasil. Para as variáveis de remuneração, foram utilizadas três variáveis dummy baseadas nas percepções dos determinantes dos elementos da remuneração de executivos, observadas nos formulários de referência da CVM. Foram adotadas variáveis para empresas que utilizam remunerações baseadas em indicadores financeiros, remunerações baseadas em indicadores não financeiros e remunerações baseadas em indicadores financeiros e não financeiros.

O primeiro modelo de regressão utilizou como variável dependente o retorno sobre os ativos futuros das empresas (ROA em $\mathrm{t}+1$ ). Os resultados deste modelo encontraram relação positiva e significativa ao nível de $1 \%$ entre os da variável de desempenho financeiro, com a variável de remuneração baseada em indicadores financeiros e não financeiros (RBIF\&NF).

O segundo modelo utilizou como variável dependente o retorno sobre o patrimônio líquido futuro das empresas (ROE em $\mathrm{t}+1$ ). Os resultados deste modelo de regressão apontam para uma relação positiva e significativa ao nível de $1 \%$ entre o indicador de desempenho e a remuneração baseada em indicadores não financeiros (RBINF).

REAd | Porto Alegre - Vol. 23 - No Especial - Dezembro 2017 - p. 4-28 
Os resultados dos dois modelos evidenciam que elementos da remuneração baseados em determinantes financeiros, não estão relacionados com o desempenho da empresa no futuro, ou seja, não alinham os interesses dos executivos com os interesses dos acionistas, contribuindo para os conflitos de agência. Os resultados da relação positiva e significativa entre o desempenho futuro e as remunerações baseadas em indicadores não financeiros, estão de acordo com Watts e Ziemmerman (1990), pois os autores afirmaram que os contratos que utilizam números contábeis na determinação da remuneração dos gestores, não são eficazes no alinhamento de interesses entre o principal e agente. Os resultados estão de acordo ainda com o estudo realizado por Farrel, Kadous e Towry (2008), que afirmaram que medidas de desempenho não financeiras podem ser os principais indicadores do futuro desempenho da empresa.

O terceiro e último modelo de regressão, utilizou como variável dependente a variação acionária futuros da empresa (VA em $\mathrm{t}+1$ ), onde se constatou que não houve relação significativa entre a variável de desempenho de mercado e as variáveis de remuneração de executivos. A não relação do desempenho de mercado com os sistemas de remuneração dos executivos evidencia que as práticas de remuneração adotadas no Brasil não alinham os interesses do principal com o interesse do agente. Os resultados denotam que o sistema de remuneração não é uma boa ferramenta para minimizar os conflitos de agência existentes.

Os resultados contradizem alguns estudos anteriores, que encontraram relação positiva da remuneração total dos executivos com o desempenho financeiro das companhias (CAMARGOS; HELAL, 2007; NASCIMENTO; FRANCO; CHEROBIM, 2012; GONZAGA; YOSHINAGA; EID JUNIOR, 2013; KRAUTER, 2013; SOUZA; FARIAS, 2015). As pesquisas anteriores utilizaram variáveis dummy para a adoção de remuneração variável ou não, valores totais de remuneração ou variáveis quantitativas para cada espécie de remuneração, não se preocupando com os fatores que determinam os elementos do plano de remuneração, assim como, utilizaram também o desempenho financeiro no curto prazo, não se preocupando com o longo prazo das empresas.

O estudo limita-se por ter utilizado apenas variáveis financeiras e não financeiras para o sistema de remuneração dos executivos. Sugere-se em pesquisas futuras que cada elemento determinante da remuneração seja testado e que os dados possam ser atualizados para os anos subsequentes.

REAd | Porto Alegre - Vol. 23 - No Especial - Dezembro 2017 - p. 4-28 


\section{REFERÊNCIAS}

BEBCHUK, L.; FRIED, J. M. Executive compensation as an agency problem. Journal of Economic Perspectives, v. 17, n. 3, p. 71-92, 2003.

BEBCHUK, L.A.; SPAMANN, H. Regulating bankers'pay. Georgetown Law Journal, v. 98, n. 1, p. 247-287, 2010.

BEUREN, I. M.; KAVESKI, I. D. S.; RIGO, V. P. Associação das medidas de desempenho para pagamento de bônus aos executivos com dependência de capital humano. Revista Contemporânea de Contabilidade, v. 11, n. 22, p. 3-24, 2014.

BEUREN, I. M.; MAZZIONI, S.; SILVA, MaM. Z. da. Remuneração dos executivos versus desempenho das empresas. R. Adm. Faces, v. 13, n. 2, p. 8-25, 2014.

BEZERRA, F. A. et al. Remuneração variável dos gestores e o conservadorismo contábil. In: Associação Nacional dos Programas de Pós Graduação em Ciências Contábeis (ANPCONT), 6, 2012, Florianópolis (SC). Anais... Florianópolis: ANPCONT, 2012.

BRASIL, Instrução Normativa $n^{\circ}$ 480, de 07 de janeiro de 2009. Comissão de Valores Mobiliários (CVM). Disponível em:http://www.cvm.gov.br/. Acesso em: 13 jul. 2014. CAMARGOS, MarcM. A. de; HELAL, D. Remuneração executiva, desempenho econômicofinanceiro e a estrutura de governança corporativa de empresas brasileiras. In: Encontro ANPAD, 31, 2007. Anais ANPAD. Rio de Janeiro, 2007.

CHEN, Y.; MA, Y. Revisiting the risk-taking effect of executive stock options on firm performance. Journal of Business Research, v. 64, n. 6, p. 640-648, 2011.

COUGHLAN, A. T.; SCHMIDT, R. M. Executive compensation, management turnover, and firm performance: An Empirical Investigation. Journal of Accounting and Economics, v. 1, n. 7, p. 43-66, 1985.

EISDORFER, A.; GIACCOTTO, C.; WHITE, R. Capital structure, executive compensation, and investment efficiency. Journal of Banking \& Finance, v. 37, n. 2, p. 549-562, 2013. FARRELL, Anne M.; KADOUS, Kathryn; TOWRY, Kristy L. Contracting on Contemporaneous versus Forward-Looking Measures: An Experimental Investigation. Contemporary Accounting Research, v. 25, n. 3, p.773-802, 2008. GHOSHAL, S. Bad management theories are destroying good management practices. Academy of Management learning \& education, v. 4, n. 1, p. 75-91, 2005. GONZAGA, R. P.; YOSHINAGA, C. E.; EID JUNIOR, W. Relação Entre os sistemas de incentivos oferecidos aos gestores e desempenho das empresas brasileiras. Revista

Contabilidade Vista \& Revista, v. 24, n. 3, p. 103-118, 2013.

REAd | Porto Alegre - Vol. 23 - No Especial - Dezembro 2017 - p. 4-28 
HAMBRICK, D. C.; FINKELSTEIN, S.; MOONEY, A.C. Executive Job Demands: New Insights for Explaining Strategic Decisions and Leader Behaviors. Academy of Management Review, v. 30, n. 3, p. 472-491, 2005.

HITZ, J.-M.; MÜLLER-BLOCH, S. Market reactions to the regulation of executive compensation. European Accounting Review, v. 24, n. 4, p. 1-26, 2015.

JENSEN, M. C.; MECKLING, W. H. Theory of the firm: managerial behavior, agency costs and ownership structure. Journal of Financial Economics, v. 3, n. 4, p. 305-360, 1976.

JENSEN, M. C.; MURPHY, K. J.; WRUCK, E.G. Remuneration: where we've been, how we got to here, what are the problems, and how to fix them. Harvard Nom Working Paper, v. 28, n. 4, p. 1-105, 2004.

KRAUTER, E. Remuneração de Executivos e desempenho financeiro: um estudo com empresas brasileiras. Revista de Educação e Pesquisa em Contabilidade, v. 7, n. 3, p. 259$273,2013$.

LIMA, R. E. de; ARAÚJO, M. B.V. de; AMARAL, H. F. Conflitos de agência: um estudo comparativo dos aspectos inerentes a empresas tradicionais e cooperativas de crédito. Revista de Contabilidade e Organizações, Ribeirão Preto, v. 2, n. 4, p. 148-157, 2008.

MACHADO, D. G.; BEUREN, I. M. Política de remuneração de executivos: um estudo em empresas industriais brasileiras, estadunidenses e inglesas. Gestão \& Regionalidade, Bento Gonçalves/RS, v. 31, n. 92, p. 1-16, 2013.

MOURA, F. de et al. Conflitos de agência, legitimidade e o discurso sobre governança corporativa: o caso Petrobras. In: Congresso USP de Iniciação Científica em Contabilidade, 11, 2014. Anais... . São Paulo, 2014.

NASCIMENTO, C.do; FRANCO, L. M. G.; CHEROBIM, A. P. Associação Entre Remuneração Variável e Indicadores Financeiros: Evidências do Setor Elétrico. Revista Universo Contábil, v. 8, n. 1, p. 22-36, 2012.

NUNES, A. de A. Concessão de opções de ações a funcionários: um problema contábil. Revista de Administração e Contabilidade da Unisinos, v. 5, n. 1, p. 32-41, 2008. OLIVA, E.; ALBUQUERQUE, L. Sistema de Remuneração de Executivos e Conselheiros Como Suporte à Estrutura de Governança Corporativa. Revista de Administração e Contabilidade da Unisinos, v. 4, n. 1, p. 61-73, 2007.

ORDU, U.; SCHWEIZER, D. Executive compensation and informed trading in acquiring firms around merger announcements. Journal of Banking \& Finance, v. 55, p.260-280, jun. 2015.

REAd | Porto Alegre - Vol. 23 - No Especial - Dezembro 2017 - p. 4-28 
PFEFFER, J. Why do bad management theories persist? A comment on Ghoshal. Academy of Management Learning \& Education, v. 4, n. 1, p. 96-100, 2005.

RAVIV, A.; SISLI-CIAMARRA, E. Executive compensation, risk taking and the state of the economy. Journal of Financial Stability, v. 9, n. 1, p. 55-68, abr. 2013.

RIBEIRO, M. G. C.; MACEDO, M. Á. da S.; MARQUES, J. A. Análise da relevância de indicadores financeiros e não financeiros na avaliação de desempenho organizacional: um estudo exploratório no setor brasileiro de distribuição de energia elétrica. Revista de Contabilidade e Organizações, Ribeirão Preto, v. 6, n. 15, p. 60-79, 2012.

SAUSET, J.; WALLER, P.; WOLFF, M. CEO contract design regulation and risktaking. European Accounting Review, v. 24, n. 4, p. 685-725, 19 maio 2014.

SILVA, A. L. C. da; CHIEN, A. C. Y. Remuneração executiva, valor e desempenho das empresas brasileiras listadas. Revista Brasileira de Finanças, Rio de Janeiro, v. 11, n. 4, p. 481-502, 2013.

SOUZA, F.; BORBA, J. A. Governança corporativa e remuneração de executivos: uma revisão de artigos publicados no exterior. Revista Contabilidade Vista \& Revista, Belo Horizonte, v. 18, n. 2, p. 35-48, 2007.

SOUZA, P. V. S. de; FARIAS, K. T. R. Remuneração dos executivos e desempenho financeiro das companhias abertas brasileiras. In: Congresso USP de Iniciação Científica em Contabilidade, 12. 2015, São Paulo. Anais... São Paulo: -, 2015. p. 1 - 16.

SUNDER, S. Teoria da contabilidade e do controle. São Paulo: Atlas, 2014.

TEIXEIRA, A. J. C. et al. Sistemas de incentivos gerenciais e o risco das empresas do estado do Espírito Santo. Revista de Educação e Pesquisa em Contabilidade, Brasília, v. 5, ed. especial, p. 23-44, 2011.

WATTS, R. L.; ZIMMERMAN, J. L. Towards a positive theory of the determination of accounting standards. The Accounting Review, v. 3, n. 1, p. 112-134, 1978.

WATTS, R. L.; ZIMMERMAN, J. L. The demand for and supply of accounting theories: the market for excuses. The Accounting Review, v. 4, n. 2, p. 273-305, 1979.

WATTS, R. L.; ZIMMERMAN, J.L. Positive accounting theory: a ten years perspective. The Accounting Review, v. 65, n. 1, p. 131-156, 1990. 